\title{
Evaluation of Drought Tolerant in Some Wheat Genotypes to Post-anthesis Drought Stress
}

\author{
Sareh Sadat Sayyah ${ }^{1}$, Mokhtar Ghobadi ${ }^{2}$, Sirous Mansoorifar ${ }^{2}$ \& Ali Reza Zebarjadi ${ }^{2}$ \\ ${ }^{1}$ Department of Agronomy and Plant Breeding, College of Agriculture, Razi University, Kermanshah, Iran \\ ${ }^{2}$ Department of Agronomy and Plant Breeding and Department of Biotechnology for Drought Resistance, Razi \\ University, Kermanshah, Iran \\ Correspondence: Mokhtar Ghobadi, Department of Agronomy and Plant Breeding, College of Agriculture, Razi \\ University, Kermanshah, Iran. Tel: 98-831-833-1723. E-mail: m.ghobadi@yahoo.com
}

Received: July 26, 2012 Accepted: August 6, 2012 Online Published: October 16, 2012

doi:10.5539/jas.v4n11p248 URL: http://dx.doi.org/10.5539/jas.v4n11p248

\begin{abstract}
Water deficit is the major cause of wheat (Triticum aestivum L.) yield losses in Iran and many other regions where the crop is not normally irrigated. The aim of the present study was to evaluate the ability of several selection indices to identify drought-resistant wheat genotypes. Twenty-one bread wheat genotypes were evaluated under two field experiments (post-anthesis drought stress and normal conditions). The experiments were arranged in a randomized complete block design with three replications in two successive growing seasons (2007/2008 and 2008/2009). The results showed that yields in the normal conditions were positively correlated with yields in the stress conditions. Several genotypes with good performance under both conditions were identified. Correlation analysis indicated that the most suitable drought tolerance criteria for screening substitution genotypes were mean productivity (MP), geometric mean productivity (GMP) and stress tolerance index (STI) (Group A genotypes) and when the stress was severe, stress susceptibility index (SSI) was found to be more useful index in discriminating resistant genotypes. Based on different drought indices, genotypes G4, G14 and G9 had the best ranking. In addition bi-plot and cluster analysis cleared superiority of these three genotypes in both seasons.
\end{abstract}

Keywords: drought stress, cluster analysis, tolerance indices, principal component analysis, wheat genotypes

Abbreviations: MP: mean productivity; GMP: geometric mean productivity; STI: stress tolerance index; TOL: stress tolerance; SSI: stress susceptibility index; PCA: principal component analysis

\section{Introduction}

Wheat (Triticum aestivum L.) is regarded as the most important cereal crop in the world. It plays a vital role in the economy to reduce the gap between food production and food import (Alam et al., 2008). Water deficit is a wide-spread problem seriously influencing wheat production and quality (Sio-Semardeh et al., 2006) which has a significant effect on the growth of wheat (B. Tas \& S. Tas, 2007). In the West of Iran such as Kermanshah Province, limited rainfall and drought stress occurs frequently during grain filling period. Under late season drought stress conditions, a fast decrease of current photosynthesis will be occurred which limits the translocation of assimilates into the grains (Johnson \& Kanemasu, 1982). Hence, the best strategy for crop productivity, yield improvement, and yield stability under soil moisture deficient conditions is to develop drought-tolerant crop varieties. Understanding the plant response in dry conditions has great importance and also a fundamental part of producing drought-tolerant cultivars (Zhao et al., 2008). Selection of wheat genotypes with better adaptation to drought stress leads to increase the productivity of wheat yield (Rajaram, 2001).

Comparison of relative performance of genotypes in drought stress and non-stress conditions can be considered as a favorable index for making a decision about selection of the tolerant genotypes in breeding plants for dry environments (Clarke et al., 1992). Fernandez (1992) classified plants based on their productions in non-stress and stress conditions to four groups: genotypes with high yield in both conditions (Group A), genotypes with high yield only in non-stress conditions (Group B), genotypes with high yield only in stress conditions (Group C), and genotypes with low yield in both conditions (Group D). To differentiate drought-tolerant genotypes, several selection indices have been suggested on the basis of a mathematical relationship between non-stress and 
stress environments (Clarke et al., 1984; Hang, 2000), such as Tolerance (TOL) (McCaig \& Clarke, 1982; Clarke et al., 1992). Mean Productivity (MP) (McCaig \& Clarke, 1982), Stress Susceptibility Index (SSI) (Fischer \& Maurer, 1978), Geometric Mean Productivity (GMP), Stress Tolerance Index (STI) (Fernandez, 1992), Yield Index (YI) (Gavuzi et al., 1997; Lin, Binns, \& Lefkovitch, 1986) and Yield Stability Index (YSI) (Bouslama \& Schapaugh, 1984) have all been employed under various conditions. The objective of the present study were: 1) to evaluate the ability of several selection indices and 2) to identify high-yielding genotypes under post-anthesis drought stress using bi-plot and cluster analysis.

\section{Materials and Methods}

Two field experiments were carried out over two seasons (2007/2008 and 2008/2009) at Agriculture College; Razi University of Kermanshah $\left(47^{\circ} 9^{\prime} \mathrm{N}, 34^{\circ} 21^{\prime} \mathrm{E}, 1319 \mathrm{~m}\right.$ asl). Monthly mean rainfall and temperature data are presented in Table 1. The experiments were arranged in a randomized complete block design with three replications under both non-stress and post-anthesis drought stress (not-irrigated after 50\% anthesis). Non-stress conditions were watered after anthesis, milk and soft dough stage. Plots were 3-m long and consisted of six rows with $0.2 \mathrm{~m}$ distance among rows. Sowing was done by hand on November 5, 2007 and November 12, 2008. Plant density was 400 seed $\mathrm{m}^{-2}$. The soil texture was clay-loamy, with $\mathrm{pH}$ of 7.2 and less than $1 \%$ organic matter. In both seasons, the experimental field was fertilized before sowing $\left(50 \mathrm{~kg} \mathrm{~N} \mathrm{ha}^{-1}\right.$ and $\left.50 \mathrm{~kg} \mathrm{Pha}^{-1}\right)$ and at stem elongation $\left(50 \mathrm{~kg} \mathrm{~N} \mathrm{ha}^{-1}\right)$. The grain yield was measured by harvesting $1 \mathrm{~m}^{2}$ of the central part of each plot at crop maturity. Drought resistances were calculated using the following indices:

$$
\begin{gathered}
S S I=[1-(Y S / Y P)] /[1-(\bar{Y} S / \bar{Y})] \text { (Fischer \& Maurer, 1978) } \\
M P=(Y P+Y S) / 2(\text { Hossain, Sears, Cox, \& Paulsen 1990) } \\
T O L=Y p-Y S \text { (Hossein et al., 1990) } \\
S T I=(Y P+Y S) /(Y P)^{2} \quad \text { (Fernandez, 1992) } \\
G M P=(Y p \times Y S)^{0.5} \quad \text { (Fernandez, 1992) } \\
Y I=Y S / \bar{Y} S \quad \text { (Lin et al., 1986) } \\
Y S I=Y S / Y P \quad(\text { Bouslama \& Schapaugh, 1984) }
\end{gathered}
$$

Where Ys is the grain yield of genotype under drought stress, Yp the grain yield of genotype under non-stress, $\overline{Y_{\mathrm{s}}}$ and $\overline{Y_{\mathrm{p}}}$ the mean yields of all genotypes under stress and non-stress conditions, respectively, and 1- $\left(\overline{Y_{\mathrm{S}}} / \overline{\mathrm{Y}}\right)$ is the stress intensity. Data were analyzed using MSTAT-C and SPSS software for analysis of variance and Duncan's multiple rang test for mean comparisons.

Table 1. Monthly rainfall and mean temperature in 2007/2009 at Kermanshah during the two growing seasons

\begin{tabular}{llllllllll}
\hline $\begin{array}{l}\text { Climatic } \\
\text { parameters }\end{array}$ & Year & NOV & DES & JAN & FEB & MAR & APR & MAY & JUN \\
\hline Rainfall $(\mathrm{mm})$ & $2007-2008$ & 6.3 & 20.3 & 23.2 & 43.4 & 34.9 & 7.5 & 6.6 & 0 \\
& $2008-2009$ & 52.8 & 60.7 & 30.8 & 73.3 & 11.7 & 55.1 & 7.2 & 1.6 \\
Mean Temp ( $\left.{ }^{\circ} \mathrm{C}\right)$ & $2007-2008$ & 13.2 & 5.9 & -1.9 & 0.5 & 8.6 & 15.8 & 18.0 & 23.6 \\
& $2008-2009$ & 11.3 & 5.7 & 2.6 & 5.7 & 8.3 & 10.2 & 15.9 & 23.0 \\
\hline
\end{tabular}

\section{Results and Discussion}

The results of analysis of variance for grain yield and resistance indices in both seasons are shown in Table 3 . Yields under normal conditions were about two times higher than yields under late drought stress in the present study. The stress intensity in the first and second year was 0.44 and 0.47 , respectively. The highest yield genotypes under non-stress conditions were G4, G10 and G14 in 2007/08 and G3, G14 and G1 in 2008/09. On the other hand, genotypes No.16 and 4 in the first year and genotypes No. 9 and 14 in the second year had maximum grain yield in late drought stress conditions. Based on ranking of MP, GMP and STI indices, G4, G14 and G10 in the first season and G14, G9 and G4 in the second time had the best performance and showed the highest value (Tables 4 and 5). In the normal conditions Yp was positive and significant correlation with Ys in the late drought stress in both seasons (Tables 6 and 7). Rosielle and Hamblin (1981) showed that the genetic correlation between YP and YS is positive and significant. In our study, a general linear model regression of 
grain yield under drought stress on yield under normal condition revealed that a positive correlation has been existed between Yp and Ys indices with a similar coefficient of determination (Figure 1).

Table 2. Name and pedigree of genotypes used for drought tolerance assessment

\begin{tabular}{|c|c|c|}
\hline Entry No. & Name/ Cross & Origin \\
\hline G1 & WS-82-9 & CIMMYT \\
\hline G2 & FLN/ACC/ANA/3/Pew"S"/4/ATTILA & CIMMYT \\
\hline G3 & KAYSON/GLENNSON//ATTILA & CIMMYT \\
\hline G4 & CHAM//PTZ NISKA/VT 1556-170 WRB856 & CIMMYT \\
\hline G5 & SHUHA $1 / /$ CHIL/2*STAR & CIMMYT \\
\hline G6 & SHUHA 1/4/VAN “S”/3/ CNDR"S"/ANA//CNDR”S"/MUS”S" & CIMMYT \\
\hline G7 & SERI 82//SHUHA “S”/4/RBS/ANZA/3/KVZ/HYS//YMG/TOB & CIMMYT \\
\hline G8 & KAYSON//GLENSON//ATTILA-4Y & CIMMYT \\
\hline G9 & $\mathrm{OMID} / / \mathrm{H} 7 / 4 / 839 / 3 / \mathrm{OMID} / \mathrm{TDO} / 5 / 40-71-23$ & CIMMYT \\
\hline G10 & $\mathrm{SITE} / / \mathrm{MO} / / 4 / / \mathrm{NAC} / \mathrm{TH} . \mathrm{AC} / / 3 * \mathrm{PVN} / 3 / \mathrm{MIRLO} / \mathrm{BUC}$ & CIMMYT \\
\hline G11 & OMBU/ALAMO//M-73-18/4/BLODAN/3/BB/7C*2//Y50/*3KAL & CIMMYT \\
\hline G12 & SNB"S"//EMU"s"/TJB84-1543/3/FALAT & CIMMYT \\
\hline G13 & F6-74/CROW"S"//GDS & CIMMYT \\
\hline G14 & PASTOR/3/VORONA/CON79//KAUZ & CIMMYT \\
\hline G15 & CHOIX/STAR/3/HEI/3*CON79//2*SERI & CIMMYT \\
\hline G16 & WEAVER/4/NAC/TH.AC//3*PVN/3/MIRLO/BUC & CIMMYT \\
\hline G17 & FISCAL & CIMMYT \\
\hline G18 & $\mathrm{PRL} / 2 * \mathrm{PASTOR}$ & CIMMYT \\
\hline G19 & PBW343*2/KHVAKI & CIMMYT \\
\hline G20 & INQALAB91*2/TUKURU(29) & CIMMYT \\
\hline G21 & MARVDASHT & IRAN \\
\hline
\end{tabular}

Table 3. Analysis of variance of YP, YS and drought tolerance indices for 21 bread wheat genotypes

\begin{tabular}{ccccccccccc}
\hline SOV & DF & YP & YS & TOL & MP & GMP & SSI & STI & YSI & YI \\
\hline First year & 2 & 106423.9 & 47332.4 & 17613.6 & 72475.7 & 72029.8 & 0.137 & 0.016 & 0.002 & 0.001 \\
Rep & & & & & & & & & \\
Genotype & 20 & $62407.7^{* *}$ & $11509.0^{* *}$ & $38761.2^{* *}$ & $27267.9^{* *}$ & $22303.8^{*}$ & $0.132^{* *}$ & $0.095^{* *}$ & $0.039^{\text {ns }}$ & $0.087^{* *}$ \\
Error & 40 & 11208.1 & 4484.2 & 15949.7 & 3858.6 & 3494.6 & 0.0 .83 & 0.018 & 0.029 & 0.035 \\
CV (\%) & & 10.93 & 12.18 & 12.65 & 12.03 & 12.06 & 9.52 & 13.88 & 15.07 & 18.80 \\
Second year & & & & & & & & & & \\
Rep & 2 & 1036.2 & 2726.7 & 6614.0 & 227.8 & 634.5 & 0.002 & 0.006 & 0.007 & 0.001 \\
Genotype & 20 & $47586.0^{* *}$ & $25966.9^{* *}$ & $55519.5^{* *}$ & $22896.9^{* *}$ & $22045.0^{* *}$ & $0.266^{* *}$ & $0.099^{* *}$ & $0.061^{* *}$ & $0.193^{* *}$ \\
Error & 40 & 6751.8 & 3780.9 & 5759.5 & 3826.5 & 3841.3 & 0.027 & 0.017 & 0.006 & 0.028 \\
CV (\%) & & 9.71 & 11.75 & 12.68 & 11.57 & 12.33 & 10.26 & 14.65 & 14.90 & 13.81 \\
\hline
\end{tabular}

*, ** significant at $5 \%$ and $1 \%$ levels, respectively.

Zangi (2005) reported that a larger value of TOL represents more sensitivity to stress, thus a smaller value of TOL is favored for selection of the genotypes. G13 and G20 had the smallest TOL value in the first and second years, respectively, so they were recognized as the best genotypes based on this index (Tables 4 and 5). TOL was strongly correlated with yield in non-stress conditions and had less negative correlation with yield under stress 
(Tables 6 and 7). TOL failed to recognize the best genotypes, because this parameter would tend to select for low-yielding genotypes. In this respect, similar results were reported by Clarke et al. (1992) in wheat; Rosielle and Hamblin (1981); Rizza et al. (2004) in barley genotypes and Sio-Semardeh et al. (2006) in wheat. Since MP is the mean performance under both stress and non-stress environments (Rosielle \& Hamblin, 1981), we also observed that MP has strongly positive correlation with yield under stress and non-stress conditions in the two seasons (Tables 6 and 7). Therefore, it seems that selection planning based on this parameter can lead to screening of high-yielding genotypes in both conditions. Sio-Semardeh et al. (2006) reported that genotypes with relatively low yield exhibited high MP values under stress conditions. But, this was not found in our study, because genotypes showed similar values in both environments. As described by Farshadfar and Sutka (2002), selection for MP increased yield in both stress and non-stress environments. Thus, G4, G10 and G14 in the first and G14, G9 and G4 in the second season exhibited high MP values. Hossain et al. (1990) used MP as a resistance criterion for wheat genotypes in moderate stress conditions. As expected, geometric mean productivity (GMP) was strongly correlated with both YP and YS. Therefore, a strong positive correlation between GMP and MP was observed in our study (Tables 6 and 7). Similar results were obtained by Mohammadi et al. (2011) for STI, GMP and MP indices.

The stress tolerance index (STI) which was introduced by Fernandez (1992) was perfectly correlated with YP and YS in both years (Tables 6 and 7). In this regard, Moghaddam and Hadi-Zadeh (2002) found that STI was more useful index in order to select favorable cultivars under stressful and stress-free conditions. In the present study, a linear model regression based on STI for grain yield under drought stress revealed a positive correlation between these criteria with a similar coefficient of determination $\left(\mathrm{R}^{2}=0.76\right)$ (Fig. 2). Our results showed G14, G4 and G10 in the first year and G14, G9 and G4 in the second year had the highest STI (Tables 4 and 5). The stress susceptibility index (SSI) introduced by Fisher and Maurer (1978) was negatively correlated with yield under stress and positively correlated with yield in normal conditions in the two seasons. Regarding the fact that a low value of SSI is preferable; genotypes with low SSI values were considered as stress tolerant, because such genotypes showed a lower reduction in grain yield under stress environment compare to non-stress environment. SSI has been widely used by researchers to identify sensitive and resistant genotypes (Winter et al., 1998; Clarke et al., 1992). The current study showed that the mean SSI appeared to be a suitable selection index to distinguish resistant genotypes. Yadav and Bhatnagar (2001) suggested the use of SSI in combination with yield under stress conditions.

Table 4. Resistance indices of 21 wheat genotypes under post-anthesis drought stress and non-stress conditions (2007-2008)

\begin{tabular}{|c|c|c|c|c|c|c|c|c|c|}
\hline Genotype No. & $\begin{array}{c}\mathrm{YP} \\
\left(\mathrm{g} \cdot \mathrm{m}^{-2}\right)\end{array}$ & $\begin{array}{c}\mathrm{YS} \\
\left(\mathrm{g} \cdot \mathrm{m}^{-2}\right)\end{array}$ & STI & TOL & MP & GMP & SSI & YSI & YI \\
\hline G1 & $627.2[15]$ & $416.9[4]$ & $0.59[10]$ & $210.2[16]$ & $522.0[13]$ & $508.2[10]$ & $0.67[17]$ & $0.67[6]$ & $1.13[4]$ \\
\hline $\mathrm{G} 2$ & $673.5[12]$ & $374.6[11]$ & $0.56[13]$ & $290.0[11]$ & $524.1[11]$ & $499.1[11]$ & $0.95[12]$ & $0.56[10]$ & $1.02[11]$ \\
\hline G3 & $777.4[4]$ & 393.8 [7] & $0.69[5]$ & 383.6 [7] & $585.6[4]$ & $552.8[5]$ & $1.05[5]$ & $0.50[17]$ & $1.06[8]$ \\
\hline G4 & $861.3[1]$ & $464.3[2]$ & $0.99[1]$ & $397.0[4]$ & $662.8[1]$ & $630.6[1]$ & $0.96[11]$ & $0.55[11]$ & $1.26[2]$ \\
\hline G5 & $598.9[17]$ & $328.1[16]$ & $0.44[18]$ & $270.8[14]$ & $463.5[17]$ & $442.3[18]$ & 0.98 [9] & $0.53[14]$ & 0.87 [18] \\
\hline G6 & $618.0[16]$ & $326.3[18]$ & $0.45[17]$ & 291.7 [12] & $472.2[16]$ & $447.9[16]$ & $0.97[10]$ & $0.54[13]$ & $0.89[16]$ \\
\hline G7 & 713.2 [9] & 369.4 [12] & $0.61[9]$ & $343.6[8]$ & $541.3[9]$ & $509.1[9]$ & $1.01[7]$ & $0.54[12]$ & $1.02[12]$ \\
\hline G8 & $668.8[13]$ & $337.8[14]$ & $0.51[14]$ & 331.0 [9] & $503.3[15]$ & $472.8[14]$ & $1.02[6]$ & $0.52[16]$ & 0.93 [13] \\
\hline G9 & $731.5[8]$ & $335.5[15]$ & $0.57[12]$ & $396.0[5]$ & $533.5[10]$ & $494.0[13]$ & $1.14[3]$ & $0.45[19]$ & 0.92 [15] \\
\hline G10 & 849.6 [2] & $411.8[5]$ & $0.79[3]$ & $437.9[2]$ & $630.7[2]$ & $589.9[2]$ & $1.09[4]$ & $0.48[18]$ & $1.11[5]$ \\
\hline G11 & $647.0[14]$ & 385.3 [9] & $0.57[11]$ & $261.7[15]$ & $516.1[14]$ & $496.8[12]$ & $0.84[15]$ & $0.61[7]$ & $1.06[7]$ \\
\hline G12 & $775.1[5]$ & $386.6[8]$ & $0.66[6]$ & $388.5[6]$ & $580.8[5]$ & $541.0[6]$ & $0.99[8]$ & $0.52[15]$ & 1.04 [9] \\
\hline G13 & $380.8[20]$ & 323.8 [19] & $0.27[20]$ & $57.01[21]$ & $352.3[20]$ & $345.3[20]$ & $0.35[21]$ & $0.85[1]$ & 0.85 [19] \\
\hline G14 & $771.8[6]$ & $452.0[3]$ & $0.80[2]$ & 319.8 [10] & 611.9 [3] & $589.8[3]$ & 0.88 [14] & 0.58 [9] & $1.23[3]$ \\
\hline G15 & $533.3[18]$ & $380.4[10]$ & $0.46[16]$ & 152.9 [19] & $456.8[18]$ & $445.9[17]$ & $0.50[20]$ & $0.75[2]$ & $1.02[10]$ \\
\hline G16 & $680.2[11]$ & $470.2[1]$ & $0.71[4]$ & 209.9 [17] & $575.2[6]$ & $564.1[4]$ & 0.68 [16] & 0.69 [5] & $1.72[1]$ \\
\hline G17 & 694.9 [10] & $406.4[6]$ & 0.63 [7] & 288.5 [13] & $550.6[8]$ & $529.2[7]$ & 0.88 [13] & $0.59[8]$ & $1.10[6]$ \\
\hline G18 & 741.9 [7] & $304.6[20]$ & $0.51[15]$ & $437.3[3]$ & $523.2[12]$ & $470.3[15]$ & $1.22[2]$ & $0.42[20]$ & 0.82 [20] \\
\hline G19 & 280.8 [21] & $197.6[21]$ & $0.13[21]$ & 83.1 [20] & $230.2[21]$ & $234.8[21]$ & 0.55 [19] & 0.74 [3] & 0.53 [21] \\
\hline G20 & $523.2[19]$ & $328.1[17]$ & 0.38 [19] & $195.1[18]$ & $425.6[19]$ & 411.6 [19] & 0.64 [18] & 0.69 [4] & 0.88 [17] \\
\hline G21 & 803.9 [3] & $340.3[13]$ & $0.62[8]$ & $463.6[1]$ & $572.1[7]$ & $522.1[8]$ & $1.23[1]$ & $0.42[21]$ & 0.92 [14] \\
\hline
\end{tabular}


Table 5. Resistance indices of 21 wheat genotypes under post-anthesis drought stress and non stress conditions (2008-2009)

\begin{tabular}{|c|c|c|c|c|c|c|c|c|c|}
\hline Genotype No. & $\begin{array}{c}\text { YP } \\
\left(\mathrm{g} \cdot \mathrm{m}^{-2}\right)\end{array}$ & $\begin{array}{c}\text { YS } \\
\left(\mathrm{g} \cdot \mathrm{m}^{-2}\right)\end{array}$ & STI & TOL & MP & GMP & SSI & YSI & YI \\
\hline G1 & $818.6[3]$ & $352.2[9]$ & $0.58[6]$ & $466.4[2]$ & $585.4[6]$ & $535.8[6]$ & $1.16[7]$ & $0.43[16]$ & 0.96 [9] \\
\hline G2 & $548.3[20]$ & $310.1[15]$ & $0.34[20]$ & $238.1[16]$ & $429.2[20]$ & $411.8[20]$ & $0.89[14]$ & $0.57[8]$ & 0.84 [15] \\
\hline G3 & $965.8[1]$ & $295.4[18]$ & $0.57[8]$ & $670.3[1]$ & $630.6[4]$ & $533.9[7]$ & $1.43[1]$ & $0.30[21]$ & 0.80 [18] \\
\hline G4 & 801.9 [4] & $491.9[3]$ & $0.80[3]$ & $310.0[13]$ & $646.9[3]$ & $627.3[3]$ & $0.81[16]$ & $0.61[6]$ & $1.34[3]$ \\
\hline G5 & $783.0[7]$ & $335.9[11]$ & $0.54[10]$ & $447.1[3]$ & $559.4[8]$ & $508.3[10]$ & $1.18[4]$ & $0.43[18]$ & 0.92 [11] \\
\hline G6 & $718.5[10]$ & 322.0 [13] & $0.46[12]$ & 396.5 [8] & $520.2[12]$ & 479.8 [12] & 1.13 [9] & $0.45[13]$ & 0.87 [13] \\
\hline G7 & 651.5 [13] & $276.8[20]$ & $0.37[18]$ & $374.7[10]$ & $464.2[18]$ & $423.5[18]$ & $1.17[5]$ & $0.43[17]$ & $0.75[20]$ \\
\hline G8 & $742.6[8]$ & $299.0[16]$ & $0.45[15]$ & $443.6[4]$ & $520.8[11]$ & $470.7[15]$ & $1.23[2]$ & $0.40[20]$ & $0.81[16]$ \\
\hline G9 & $713.9[11]$ & $581.3[1]$ & $0.84[2]$ & $132.6[20]$ & $647.6[2]$ & $643.3[2]$ & $0.36[20]$ & $0.82[2]$ & $1.58[1]$ \\
\hline G10 & $791.6[5]$ & $379.1[8]$ & $0.61[5]$ & $412.5[6]$ & $585.4[7]$ & $547.3[5]$ & $1.07[10]$ & $0.48[12]$ & $1.03[8]$ \\
\hline G11 & $631.3[16]$ & 331.7 [12] & $0.42[17]$ & 299.6 [15] & 481.5 [17] & $457.6[17]$ & 0.98 [12] & $0.52[10]$ & 0.90 [12] \\
\hline G12 & $634.9[15]$ & $436.6[5]$ & 0.57 [9] & $198.3[17]$ & 535.7 [9] & $525.0[8]$ & 0.65 [18] & $0.68[4]$ & 1.18 [5] \\
\hline G13 & $578.1[18]$ & $394.4[6]$ & $0.46[13]$ & $183.8[18]$ & $486.3[16]$ & $475.6[13]$ & 0.61 [19] & $0.70[3]$ & 1.07 [6] \\
\hline G14 & 887.0 [2] & $552.5[2]$ & 0.99 [1] & $334.5[12]$ & 719.7 [1] & 699.3 [1] & 0.77 [17] & $0.62[5]$ & $1.50[2]$ \\
\hline G15 & $787.5[6]$ & 392.4 [7] & $0.63[4]$ & 395.1 [9] & $589.9[5]$ & 554.8 [4] & 1.04 [11] & $0.49[11]$ & 1.06 [7] \\
\hline G16 & $646.3[14]$ & $345.3[10]$ & $0.45[14]$ & $301.0[14]$ & $495.8[15]$ & $472.4[14]$ & 0.96 [13] & 0.53 [9] & 0.94 [10] \\
\hline G17 & $713.0[12]$ & 296.2 [17] & $0.42[16]$ & $416.7[5]$ & $504.6[14]$ & $457.8[16]$ & $1.21[3]$ & $0.42[19]$ & 0.80 [17] \\
\hline G18 & 730.1 [9] & $318.0[14]$ & $0.47[11]$ & 412.1 [7] & $524.0[10]$ & $481.2[11]$ & $1.16[6]$ & $0.43[15]$ & $0.86[14]$ \\
\hline G19 & $412.8[21]$ & $238.1[21]$ & $0.20[21]$ & $174.7[19]$ & $325.5[21]$ & $313.2[21]$ & 0.88 [15] & 0.57 [7] & 0.64 [21] \\
\hline G20 & $555.9[19]$ & $481.1[4]$ & 0.57 [7] & $74.78[21]$ & $518.5[13]$ & 516.9 [9] & $0.25[21]$ & 0.88 [1] & $1.30[4]$ \\
\hline G21 & $625.2[17]$ & 279.2 [19] & 0.36 [19] & 346.0 [11] & 452.2 [19] & 416.9 [19] & 1.15 [8] & $0.44[14]$ & 0.76 [19] \\
\hline
\end{tabular}

Table 6. Correlation coefficients among YP, YS and drought tolerance indices (2007-2008)

\begin{tabular}{llllllllll}
\hline & YP & YS & TOL & MP & GMP & YSI & YI & SSI & STI \\
\hline YP & 1 & & & & & & & & \\
YS & $0.692^{* *}$ & 1 & & & & & & & \\
TOL & $0.858^{* *}$ & -0.425 & 1 & & & & & & \\
MP & $0.942^{* *}$ & $0.756^{* *}$ & $0.635^{* *}$ & 1 & & & & & \\
GMP & $0.875^{* *}$ & $0.849^{* *}$ & $0.504^{*}$ & $0.986^{* *}$ & 1 & & & & \\
YSI & $-0.657^{* *}$ & 0.257 & $-0.905^{* *}$ & -0.395 & -0.270 & 1 & & & \\
YI & $0.506^{*}$ & $0.897^{* *}$ & -0.063 & $0.652^{* *}$ & $0.738^{* *}$ & 0.278 & 1 & & \\
SSI & $0.654^{* *}$ & $-0.511^{*}$ & $0.876^{* *}$ & 0.410 & 0.297 & $-0.974^{* *}$ & 0.266 & 1 & \\
STI & $0.791^{* *}$ & $0.723^{* *}$ & $0.482^{*}$ & $0.874^{* *}$ & $0.881^{* *}$ & -0.269 & $0.806^{* *}$ & 0.289 & 1 \\
\hline
\end{tabular}

$*, * *$ significant at $5 \%$ and $1 \%$ levels, respectively 
Table 7. Correlation coefficients among YP, YS and drought tolerance indices (2008-2009)

\begin{tabular}{|c|c|c|c|c|c|c|c|c|c|}
\hline & YP & YS & TOL & MP & GMP & YSI & YI & SSI & STI \\
\hline YP & 1 & & & & & & & & \\
\hline YS & $0.610^{n *}$ & 1 & & & & & & & \\
\hline TOL & $0.739^{n *}$ & $-0.471^{\circ}$ & 1 & & & & & & \\
\hline MP & $0.865^{* *}$ & $0.738^{* *}$ & 0.301 & 1 & & & & & \\
\hline GMP & $0.724^{n \pi}$ & $0.873^{n \pi}$ & $0.720^{n \pi}$ & $0.971^{* *}$ & 1 & & & & \\
\hline YSI & $-0.427^{\circ}$ & $0.706^{n \pi}$ & $-0.904^{n \approx}$ & $0.690^{\circ-}$ & 0.282 & 1 & & & \\
\hline YI & $0.507^{\circ}$ & $0.996^{n \pi}$ & -0.411 & $0.741^{\circ-}$ & $-0.874^{\pi \pi}$ & $0.697^{\circ-\infty}$ & 1 & & \\
\hline SSI & $0.518^{\circ}$ & $-0.704^{n *}$ & $0.895^{n \pi}$ & $-0.750^{\circ \infty}$ & -0.286 & $-0.992^{n *}$ & $-0.705^{\circ \circ}$ & 1 & \\
\hline STI & $0.678^{n *}$ & $0.893^{n-}$ & 0.013 & $0.949^{-n}$ & $0.991^{n *}$ & 0.326 & $0.892^{-n}$ & -0.327 & 1 \\
\hline
\end{tabular}

*,** significant at $5 \%$ and $1 \%$ levels, respectively.

YI, which was proposed by Gavuzzi et al. (1997), was significantly correlated with both conditions. YSI, as Bouslama and Schapaugh (1984) stated, evaluates the yield of genotypes under stress relative to non-stress conditions, and should be an indicator of drought resistance of genetic materials. So, the genotypes with a high YSI are expected to have high yield under both stress and non-stress conditions. But, in the present study, genotypes with the highest YSI exhibited the least yield under non-stress conditions and the highest yield under stress conditions (Tables 4 and 5). Our results were in consistence with those reported by Sio-Semaredeh et al. (2006) on wheat cultivars.

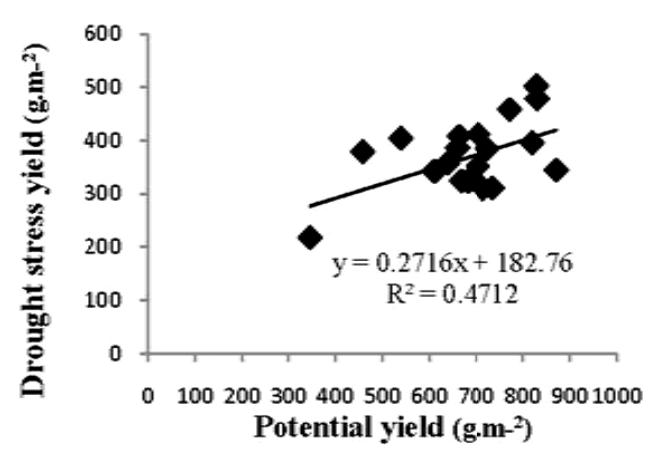

Figure 1. Relationship between grain yields of non-stress and drought stress wheat genotypes. Each point is the mean yield (average two years).

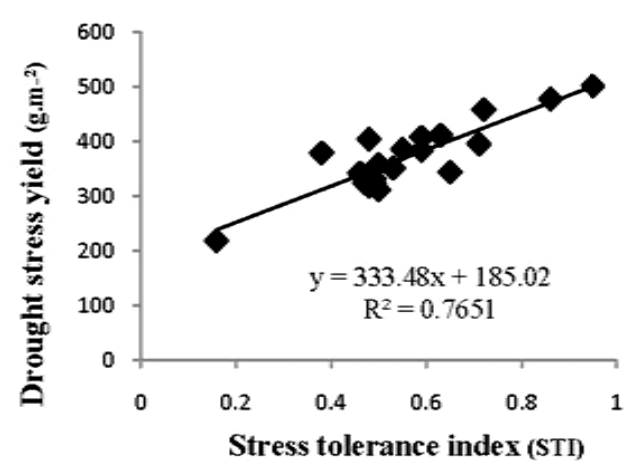

Figure 2. Relationship between grain yields under drought stress and stress tolerance index (STI) (average two years).

\subsection{Principal Component Analysis}

From the farme's point of view, best genotypes should be high-yield production in normal and stress conditions. From the two-way distribution of genotypes according to the yield in the two contrasting years, we can introduce four genotypes, which produced over $700 \mathrm{~g} \mathrm{~m}^{-2}$ under normal environment and over $400 \mathrm{~g} \mathrm{~m}^{-2}$ under drought stress during grain filling period (average two years). These genotypes had the highest STI value among the 21 genotypes. Among these four genotypes, three of which were placed in top ranking in respect of MP and GMP indices. Therefore, from this point of view MP, GMP and STI seem to be more desirable indices, but probably not better than simple analysis of two-way distribution according to yield versus two seasons. Principal component analysis (PCA) revealed that the first PCA explained $62.8 \%$ of the variation with YS, YP, MP, STI and GMP (Table 7). The first PCA separated the genotypes with high YP and low SSI and TOL.

Thus, the first dimension can be named as the yield potential in drought tolerance, which has positive correlation with YS, MP, GMP and STI. Genotypes that have high values of these indices will be considered as high yielding under stress and non-stress environments. The second PCA explained $35.6 \%$ of total variability and positively correlated with TOL, SSI and YSI. Therefore, can be named as a stress-tolerant dimension and separate the stress-tolerant genotype from non-stress tolerant ones. Thus, genotypes no.'s 14, 4 and 9 were 
considered as superior genotypes for both environments with high PC1 and low PC2. Genotypes belonging to G3 and G10 with high PC2 were more suitable for non-moisture stress than for moisture-stress environment. Talebi et al. (2009) and Farshadfar and Sutka (2002) obtained similar results in multivariate analysis of drought tolerance in wheat. G14 and G4 were placed in group A, G3 placed in group B, and G19 in group D. G14 showed high STI (Figure 3). Farmers may prefer G14 and G4 in Kermanshah province because of its relatively high yield when water is not so limiting and suffers minimum loss during late drought seasons. If the strategy of breeding program is to improve yield in a stressed and non-stressed environments, it may be possible to explain local adaptation for increasing efficiency selection in those environments (Hohls, 2001). However, selection should be carried out based on the resistance indices calculated from the yield under both conditions, because the breeders are looking for the genotypes which are adapted to a wide range of environments or located on unpredictable conditions.

Table 8. Principal components and the coefficient for each indices and yield in stress and normal conditions (average two years)

\begin{tabular}{cccccccccc}
\hline Components & Yp & Ys & STI & TOL & MP & GMP & SSI & YSI & Cumulative\% \\
\hline PC1 & 0.878 & 0.826 & 0.985 & 0.421 & 0.995 & 0.994 & 0.152 & -0.163 & 62.82 \\
PC2 & 0.470 & -0.556 & -0.110 & 0.898 & 0.076 & -0.044 & 0.984 & -0.981 & $35 / 64$ \\
& & & & & & & & & $98 / 47$ \\
\hline
\end{tabular}

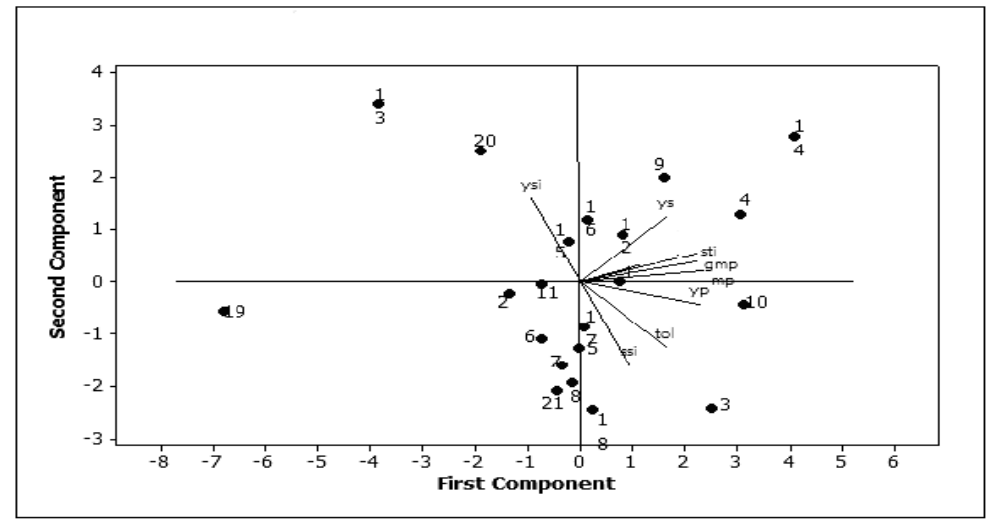

Figure 3. Drawing bi-plot based on first and second components for 21 wheat genotypes and different indices (average two years)

\subsection{Cluster Analysis}

Calculation of cluster numbers is based on number of principal components and confirmed the results of PCA (Figure 4). Analysis of tolerance indices indicated that there were significant differences among genotypes. Cluster analysis of genotypes based on GMP, MP, STI, yield under post-anthesis drought and yield under non-drought stress conditions classified the genotypes into three group. In the first group there were genotypes no. $5,7,6,17,18,21,8,2,11,3$ and 10. In addition, in the first group most of the genotypes had high SSI and TOL, thus they were susceptible to drought and only suitable for irrigated conditions. In the second group there were genotypes no. 4, 14, 12,16,15, 1 and 9. In this analysis, the second group had the highest MP, GMP and STI, and considered to be a most desirable cluster for both conditions. On the other hand, the third group there were genotypes no. 13, 20 and 19. These genotypes had low yield under non-stress conditions and had small TOL and SSI (Tables 4 and 5) 


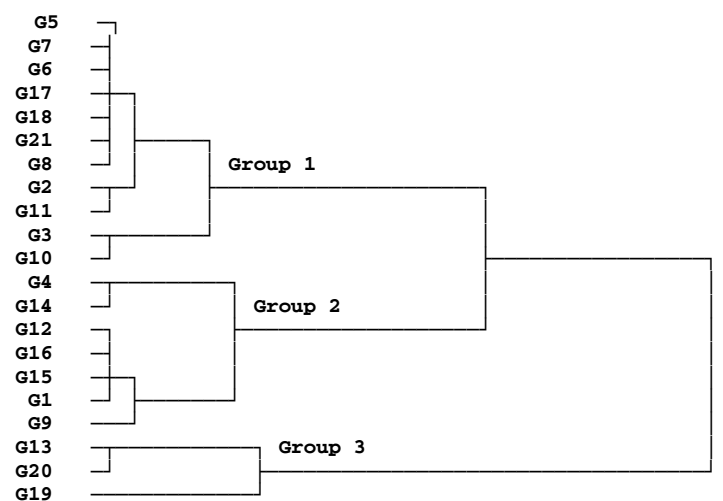

Figure 4. Dendrogram of measured trait means for 21 wheat genotypes using the WARDS method (average two years)

\section{Conclusions}

Yield under stress condition was dependent on yield under non-stress condition. However, STI, GMP and MP were able to identify genotypes with high yielding in both environments. SSI was found to be more useful index for discriminating resistant genotypes, although none of the indicators could clearly identify high yield genotypes under both stress and non-stress conditions (group A genotypes). In conclusion, it is concluded that the effectiveness of selection indices depends mainly on the stress severity. This supports the idea that only under moderate stress conditions, potential yield greatly influences yield under stress condition where YP and YS were better predictors than TOL, SSI and YSI for YP and YS than TOL, SSI and YSI. G4, G14 and G9 were identified as suitable genotypes for dry land areas of Iran such as Kermanshah Province, where drought stress more frequently occurs during post-anthesis stage.

\section{Acknowledgment}

We would like to thank Center of Agricultural Research and Natural Resources of Kermanshah, Iran for providing the seeds of all wheat genotypes involved in the present study.

\section{References}

Alam, M. S., Rahman, A. H. M. M., Nesa, M. N., Khan, S. K ., \& Siddique, N. A. (2008). Effect of source and/or sink restriction on the grain yield in wheat. Journal of Applied Sciences, 4, 258-261.

Bouslama, M., \& Schapaugh, W. T. (1984). Stress tolerance in soybean. Part 1: Evaluation of three screening techniques for heat and drought tolerance. Crop Science, 24, 933-937. http://dx.doi.org/10.2135/cropsci1984.0011183X002400050026x

Clarke, J. M., Townley-Smith, T. M., McCaig, T. N., \& Green, D. G. (1984). Growth analysis of spring wheat cultivars of varying drought resistance. Crop Science, $24,537-541$. http://dx.doi.org/10.2135/cropsci1984.0011183X002400030026x

Clarke, J. M., De Pauw, R. M., \& Townley-Smith, T. M. (1992). Evaluation of methods for quantification of $\begin{array}{lllll}\text { drought tolerance } \quad \text { in } \quad \text { Crop } & \text { Science, } & 32,732 .\end{array}$ http://dx.doi.org/10.2135/cropsci1992.0011183X003200030029x

Farshadfar, E., \& Sutka, J. (2002). Multivariate analysis of drought tolerance in wheat substitution lines. Cereal Research Communications, 31, 33-39.

Fernandez, G. C. J. (1992). Effective selection criteria for assessing stress tolerance. In: Kuo CG (ed), Proceedings of the international smposium on adaptation of vegetables and other food Crops in temperature and water stress (pp. 257-270). Asian Vegetable Research and Development Center, Shanhua, Tainan, Taiwan, 1992

Fischer, R. A., \& Maurer, R. (1978). Drought resistance in spring wheat cultivars. Part I: grain yield response. Australian Journal of Agriculture research, 29, 897- 912. http://dx.doi.org/10.1071/AR9780897

Gavuzzi, P., Rizza, F., Palumbo, M., Campaline, R. G., Ricciardi, G. L., \& Borghi, B. (1997). Evaluation of field and laboratory predictors of drought and heat tolerance in winter cereals. Canadian Journal of Plant Science, 77, 523- 531. http://dx.doi.org/10.4141/P96-130 
Hossain, A. B. S., Sears, A. G., Cox, T. S., \& Paulsen, G. M. (1990). Desiccation tolerance and it's relationship to assimilate partitioning in winter wheat. Crop Science, 30, 622-627. http://dx.doi.org/10.2135/cropsci1990.0011183X003000030030x

Hohls, T. (2001). Condition under which selection for mean productivity tolerance to environment stress, or stability should be used to improve year across a range of contrasting environments. Euphytica, 120, 235-245.http://dx.doi.org/10.1023/A:1017569415098

Huang, B. (2000). Role of root morphological and physiological characteristics in drought resistance of plants. In: Wilkinson, R. E. (Ed.), Plant-Environment Interactions (pp. 39-64). New York: Marcel Dekker Inc. http://dx.doi.org/10.1201/9780824746568.ch2

Johnson, R. C., \& Kanemasu, E. T. (1982). The influence of water availability on winter wheat yields. Canadian Journal of Plant Science, 62, 831-838. http://dx.doi.org/10.4141/cjps82-125

Lin, C. S., Binns, M. R., \& Lefkovitch, L. P. (1986). Stability analysis: where do we stand? Crop Science, 26, 894-900. http://dx.doi.org/10.2135/cropsci1986.0011183X002600050012x

McCaig, T. N., \& Clarke, J. M. (1982). Seasonal changes in nonstructural carbohydrate levels of wheat and oats $\begin{array}{lllll}\text { grown in semiarid environment. Crop } & \text { Science, 22, 963-970. }\end{array}$ http://dx.doi.org/10.2135/cropsci1982.0011183X002200050016x

Mohammadi, M., Karimizadeh, R., \& Abdipour, M. (2011). Evaluation of drought tolerance in bread wheat genotypes under dryland and supplemental irrigated conditions. Australian Journal of Crop Science, 5, $487-493$

Rajaram, S. (2001). Prospects and promise of wheat breeding in the $21^{\text {st }}$ century. Euphytica, 119, 3-15. http://dx.doi.org/10.1023/A:1017538304429

Rizza, F., Badeck, F. W., Cattivelli, L., Lidestri, O., Fonzo, N. D, \& Stanca, A. M. (2004). Use of a water stress index to identify barley genotypes adapted to rain fed and irrigated conditions. Crop Science, 44, 2127-2137. http://dx.doi.org/10.2135/cropsci2004.2127

Rosielle, A. A., \& Hamblin, J. (1981). Theoretical aspects of selection for yield in stress and non stress environments. Crop Science, 21, 943-946. http://dx.doi.org/10.2135/cropsci1981.0011183X002100060033x

Sio-Se Mardeh, A., Ahmadi, A., Poustini, K., \& Mohammadi, V. (2006). Evaluation of drought resistance indices under various environmental conditions. Field Crops Research, 98, 222-229. http://dx.doi.org/10.1016/j.fcr.2006.02.001

Talebi, R., Fayaz, F., \& Mohammad Naji, A. (2009). Effective selection criteria for assessing drought stress tolerance in durum wheat (Triticum Durum Desf). General and Applied Plant Physiology, 35, 64-74.

Tas, S., \& Tas, B. (2007). Some Physilogical Responses of Drought Stress in Wheat Genotypes with Different Ploidity in Turkiye. World Journal of Agricultural Science, 3(2), 178-183.

Winter, S. R., Musick, J. T., \& Porter, K. B. (1998). Evaluation of screening techniques for breeding $\begin{array}{lllll}\text { drought-resistance winter } \quad \text { wheat. } & \text { Crop Science, } & \text { 28, } & \text { 512-516. }\end{array}$ http://dx.doi.org/10.2135/cropsci1988.0011183X002800030018x

Yadav, O. P., \& Bhatnagar, S. K. (2001). Evaluation of indices for identification of pearl millet cultivars adapted to stress and non-stress conditions. Field Crops Research, 70, 201-208. http://dx.doi.org/10.1016/S0378-4290(01)00138-1

Zangi, M. R. (2005). Correlations between drought resistance indices and cotton yield in stress and non stress condition. Asian Journal of Plant Science, 4, 106-108. http://dx.doi.org/10.3923/ajps.2005.106.108

Zhao, C. X., Guo, L. Y., Jaleel, C. A., Shoa, H. B., \& Yang, H. B. (2008). Prospect for dissecting plant adaptive molecular mechanisms to improve wheat cultivars in drought environments. International Journal of Agriculture \& Biology, 331, 579-586. http://dx.doi.org/10.1016/j.crvi.2008.05.006 